\title{
CARACTERIZAÇÃO DA ATIVIDADE DE CARCINICULTURA NO VALE DO RIO AÇU, RIO GRANDE DO NORTE, BRASIL
}

\author{
R. A. A. Carvalho', P. C. C. Martins ${ }^{2}$ \\ 'Instituto Federal de Educação Ciência e Tecnologia do Rio Grande do Norte-IFRN \\ ${ }^{2}$ Universidade Federal Rural do Semi-Árido-UFERSA \\ roberto.carvalho@ifrn.edu.br
}

Submetido 21/09/2015 - Aceito 25/04/2017

DOI: $10.15628 /$ holos.2017.3427

\section{RESUMO}

Dada a importância social e econômica da carcinicultura para o Nordeste brasileiro e o destaque da Bacia do Rio Açu como polo produtor no Rio Grande do Norte, tornase importante o levantamento de informações detalhadas sobre esta cadeia produtiva, que possam subsidiar ações de gestão visando seu fortalecimento e crescimento sustentável. Este trabalho tem como objetivo caracterizar a situação da carcinicultura praticada no Vale do Rio Açu com ênfase na capacidade produtiva, nível tecnológico e geração de empregos diretos. A pesquisa foi realizada através da aplicação de questionário semiestruturado em 20 fazendas de camarão localizadas em 04 municípios potiguares: Macau, Pendências, Carnaubais e Alto do Rodrigues. Segundo os resultados, em 2013 a área total de lâmina d'agua ocupada por viveiros de camarão nas 20 fazendas foi de 1843,7 hectares, produziram 6.294,1 toneladas e geram um total de 661 empregos diretos. As fazendas utilizam águas com salinidades que variam de 0 a $60 \mathrm{~g} / \mathrm{l}$, sendo a maior parte delas de médio (35\%) e grande porte (45\%) e elevado nível tecnológico. Praticamente toda a produção de camarão do Valle do Açu do ano de 2013 foi comercializada no mercado nacional, principalmente para os estados do Rio de Janeiro e São Paulo. As patologias que afetaram o maior número de fazendas foram IMNV, Vibriose e NHP e WSSV foi considerada a patologia que representava o maior risco futuro para a atividade. Os resultados demonstram que no período estudado a carcinicultura passava por uma fase de reestruturação e crescimento.

PALAVRAS-CHAVE: Carcinicultura, Aquicultura, Recursos Pesqueiros.

\section{CHARACTERIIZATION OF SHRIMP FARMING IN AÇU RIVER, RIO GRANDE DO NORTE, BRAZIL.}

\begin{abstract}
Given the social and economic importance of shrimp farming in the Brazilian Northeast and the highlight of the Açu River Basin as a production hub in Rio Grande do Norte, it is important to survey current and detailed information on the regional production chain that can support actions management aimed at their strengthening and sustainable growth. This work aims to characterize the present situation of shrimp farming practiced in Açu River Valley with an emphasis on productive capacity, technological level and direct Jobs generating. The survey was conducted through a questionnaire semistructured applied in 20 shrimp farms located in 04 municipalities of Rio Grande do Norte State: Macau, Pendências, Carnaubais and Alto do
\end{abstract}

Rodrigues. According to the results, in 2013 the total area of water

occupied by shrimp ponds in the 20 farms was 1843.7 hectares, produced 6.294.1 tons and generate a total of 661 direct jobs. These farms using water with salinity ranging from 0 to $60 \mathrm{~g} / \mathrm{l}$, most of them midsize (35\%) and large (45\%) and high technological level. Virtually the entire shrimp production of the Açu Valley in 2013 was sold in the domestic market, mainly in the states of Rio de Janeiro and Sao Paulo. The pathologies that affected the largest number of farms were IMNV, vibriosis and NHP and WSSV was considered pathology representing the highest risk for future of activity. The results show that in the period studied the shrimp went through a phase of restructuring and growth.

KEYWORDS: Shrimp farming, Aquaculture, Fishery resources 


\section{INTRODUÇÃO}

A produção de camarão marinho em cativeiro é uma atividade econômica que contribui de forma importante para a economia, geração de empregos e produção de alimentos em vários países. Em 2013 a carcinicultura produziu 4.454.602 toneladas alcançando valor de 22,662 bilhões de dólares (Food and Agriculture Organization of United Nations [FAO], 2015a). Deste total 74\% (3.314.447 toneladas) foram decorrentes do cultivo da espécie Litopenaeus vannamei (Boone, 1931) que é o sexto organismo aquático mais cultivado no mundo, sendo suplantado por algumas espécies de peixes em biomassa produzida (3.314.447 toneladas em 2013), mas superando a todos em valor monetário, estimado em 16,514 bilhões de dólares (FAO, 2015b). Esta produção está concentrada principalmente nos países do continente asiático, sendo a China o maior produtor com 39,1\% da produção mundial em 2012, entretanto a América Latina desponta como área de grande potencial para ampliação da carcinicultura com destaque para Equador, México e o Brasil (FAO, 2014).

No Brasil a introdução do L. vannamei, que se adaptou muito bem às condições locais, em especial na região Nordeste, proporcionou o desenvolvimento da carcinicultura no país. A atividade apresentou um rápido desenvolvimento saindo de uma produção de 3.600 toneladas em 1997 para 90.360 em 2003, colocando o camarão cultivado em segundo lugar na pauta das exportações do setor primário da Região Nordeste (Rocha, 2014). Entretanto a partir de 2004 a carcinicultura brasileira sofreu uma severa diminuição em sua produção e entre os fatores apontados como causa estão a valorização do dólar, a ação antidumping americana e o surto do Vírus da Mionecrose Infecciosa (IMNV) (Silva \& Sampaio, 2009; Rocha, 2010; Rodrigues \& Borba, 2015). No Rio Grande do Norte somaram-se a estes fatores as sucessivas enchentes ocorridas nos anos de 2004, 2008 e 2009 que prejudicaram severamente os empreendimentos das principais áreas produtoras no estado (Associação Brasileira dos Criadores de camarão [ABCC], 2013).

O fortalecimento da economia brasileira e a consequente ampliação da demanda interna foram responsáveis por uma retomada da produção na carcinicultura, atualmente voltada quase que exclusivamente para o mercado doméstico. Com o ajuste do sistema de produção a essa nova realidade as empresas voltaram a produzir e a participação do mercado interno que era de 31\% em 2004 passou para 99 \% em 2011 (Bezerra, 2010; Tahim \& Araújo, 2014), reforçando a importância social e econômica desta atividade principalmente para o Nordeste Brasileiro onde se concentra $99 \%$ da produção nacional (Rodrigues \& Borba, 2015).

No censo mais recente sobre a carcinicultura brasileira, realizado em 2011, o Ceará aparece como o estado brasileiro com maior área de cultivo em operação somando um total de 6.580 ha (33,2\% do total do país). Em segundo lugar estava o Rio Grande do Norte, com área de 6.540 ha (33\% do total) distribuídos em 385 empreendimentos, sendo que aproximadamente um terço desta área está localizada no Litoral Norte do estado, nos municípios próximos a Bacia do Rio Açu (ABCC, 2013).

Muitas pesquisas têm comprovado a importância da carcinicultura para a economia dos municípios onde as fazendas são instaladas (Silva \& Sampaio, 2009; Tahim \& Araújo, 2014; Sampaio, Costa, Albuquerque \& Sampaio, 2008). Em um estudo sobre os impactos socioeconômicos da carcinicultura em municípios do Nordeste brasileiro Sampaio et al (2008) demonstraram a importante contribuição da atividade na receita tributária dos municípios estudados incluindo o município de Pendências, localizado às margens do Rio Açu, onde em 2002 a esta contribuição alcançou $14,5 \%$ do total arrecadado. Os autores destacam ainda que este 
impacto positivo da carcinicultura sobre o emprego e a renda municipal possibilita um aumento nos níveis de consumo e bem estar da população destes municípios.

Dada a importância social e econômica da carcinicultura para o Nordeste brasileiro e o destaque da Bacia do Rio Açu como polo produtor no Rio Grande do Norte, torna-se importante o levantamento de informações detalhadas sobre esta cadeia produtiva regional, que possam subsidiar ações de gestão visando seu fortalecimento e crescimento sustentável. Este trabalho tem como objetivo caracterizar a carcinicultura praticada no Vale do Rio Açu com ênfase na capacidade produtiva, nível tecnológico e geração de empregos diretos.

\section{METODOLOGIA}

Para realização desta pesquisa foi utilizada a aplicação de questionário semiestruturado aplicado em fazendas de camarão localizadas no Vale do Rio Açu, litoral norte do Estado do Rio Grande do Norte, compreendendo os municípios de Macau, Pendências, Alto do Rodrigues e Carnaubais (Figura 01). As fazendas foram identificadas através de várias fontes de informações, como o banco de dados do Instituto federal de Ciência e Tecnologia do Rio Grande do Norte Campus Macau (IFRN-Macau), fornecedores de ração, responsáveis técnicos, além de empresários do setor, buscando alcançar todos os empreendimentos em atividade.

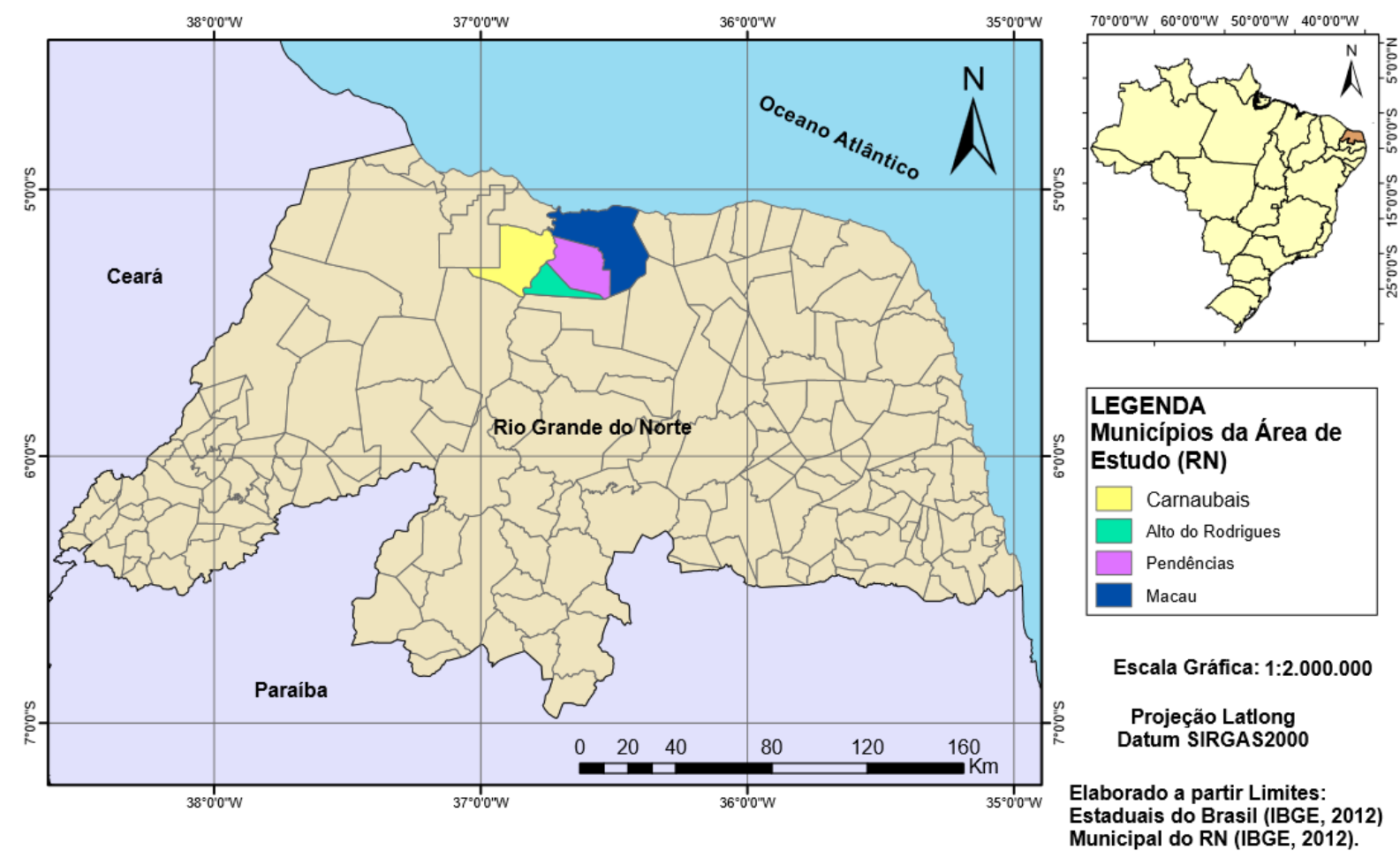

Figura 01: Localização dos municípios do Vale do Açu que compõem a área de estudo.

Posteriormente as fazendas identificadas foram visitadas para aplicação do questionário aos proprietários ou responsáveis técnicos entre os meses de fevereiro a maio de 2014, desconsiderando as unidades que estavam fora de operação. O questionário consiste de 35 perguntas referentes ao número de fazendas de camarão, número de viveiros e área destinada ao cultivo, número de empregos diretos gerados, produção anual em 2013, salinidade da água 
utilizada no cultivo, nível tecnológico utilizado na produção, mercados consumidores e problemas com enfermidades que afetam os camarões cultivados.

Para a classificação das fazendas quanto à salinidade da água que abastece os cultivos foi utilizada a definição proposta por Boyd (2001): Água doce, salinidade até 0,5 g/l; Oligohalina, entre 0,5 e 3 g/l; Mesohalina, de 3 à 16,5; Polihalina de 16,5 à $30 \mathrm{~g} / \mathrm{l}$; Eurihalina ou Marinha de 30 à $40 \mathrm{~g} / \mathrm{l}$ e Hiperhalina acima de $40 \mathrm{~g} / \mathrm{l}$.

Afim de facilitar a discussão dos resultados e a comparação com levantamentos feitos anteriormente na região, a tabulação e categorização dos dados obtidos foi, na maior parte das vezes, semelhante à utilizada pela ABCC (2013) em seu levantamento da infraestrutura produtiva da carcinicultura no Brasil realizado em 2011. Nesta metodologia a classificação das fazendas quanto ao porte do empreendimento adotada as seguintes categorias: Micro, abaixo de 5 hectares; Pequeno, entre 5 e 10 hectares; Médio, entre 10 e 50 hectares e Grande acima de 50 hectares.

Para avaliação do nível tecnológico empregado nos empreendimentos de carcinicultura foram adotados como indicadores o uso das seguintes práticas: Utilização de berçários, aeradores, probióticos, comedouros fixos, realização de análises presuntivas e análises hidrológicas. Para acessar informações sobre o mercado consumidor do camarão produzido na região os representantes das fazendas foram questionados se a produção era comercializada para exportação ou para o mercado brasileiro e em sendo para mercado brasileiro para qual estado.

Por fim, foi perguntado aos carcinicultores quais patologias tem exercido impacto negativo sobre a produção do camarão e qual mais prejuízos até o momento.

\section{RESULTADOS E DISCUSSÃO}

Foram identificadas e entrevistadas 20 fazendas distribuídas em 04 municípios potiguares (Macau, Pendências, Carnaubais e Alto do Rodrigues) localizados às margens do Rio Açu, resultando numa coleta significativa de informações sobre a atividade de carcinicultura desenvolvida na região.

A área total de lâmina d'agua ocupada por viveiros de camarão nas 20 fazendas foi de 1843,7 hectares (ha) dividida em 545 viveiros com áreas individuais que variam de 0,6 até 9,4 ha. O município de Carnaubais foi o que apresentou o maior número de fazendas, 9 empresas, seguido de Macau com 6, Pendências com 4 e Alto do Rodrigues com 1. Quanto a área de produção, o município de Pendências apresentou a maior área com 1.093 ha, seguido de Carnaubais com 503,1 ha, Macau com 244,6 ha e Alto do Rodrigues com 03 ha (Tabela 1).

Em levantamento realizado pela ABCC (2013) em 2011 no Vale do Açu foram registradas 23 fazendas nos municípios de Macau (8), Pendências (5), Carnaubais (8) e Porto do Mangue (2). No presente estudo foram identificados 20 empreendimentos, entretanto durante a aplicação dos questionários foi possível observar que ocorre com frequência a fusão de algumas fazendas em consequência de arrendamentos ou compra de áreas de uma fazenda por proprietários de outras, assim como divisão de uma fazenda em duas ou mais motivada, por exemplo, por dissolução de sociedades. Desta forma a avaliação da carcinicultura a partir do número de unidades produtivas se torna bastante imprecisa, sendo mais indicado o uso da área ocupada pela atividade. 


\begin{tabular}{lccc|ccc} 
& \multicolumn{3}{c|}{2011 (ABCC, 2013) } & \multicolumn{3}{c}{2013 (Este estudo) } \\
& Produtores & Área (ha) & Produção(t) & $\begin{array}{l}\text { Produ } \\
\text { tores }\end{array}$ & Área (ha) & Produção(t) \\
Alto do & 0 & 0 & 0 & 1 & 3 & 7,1 \\
$\begin{array}{l}\text { Rodrigues } \\
\text { Carnaubais }\end{array}$ & 8 & 431 & 990 & 9 & 503,1 & 857,4 \\
Macau & 8 & 259 & 742 & 6 & 244,6 & 558,3 \\
$\begin{array}{l}\text { Pendências } \\
\text { Porto do }\end{array}$ & 5 & 1.123 & 1.680 & 4 & 1093 & $4.871,3$ \\
Mangue & 2 & 316 & 380 & 0 & 0 & 0 \\
\hline Total & 23 & 2.129 & 3.792 & 20 & 1843,7 & $6.294,1$ \\
\hline
\end{tabular}

Tabela 01- Distribuição do número de produtores por município, com área produtiva e produção.

Quando comparamos os resultados obtidos no presente estudo com os do censo publicado pela ABCC (2013) referente ao ano de 2011, percebe-se uma diminuição da área de cultivo $(13,4 \%)$ de 2.129 ha para $1.843,7$ ha em 2013 . Esta diminuição se deve ao fechamento de algumas fazendas, atualmente desativadas, ou a mudança de atividade de algumas áreas como é o caso das 2 únicas fazendas registradas pela ABCC no município de Porto do Mangue em 2011 que foram adaptadas para produção de sal, extinguindo a atividade de carcinicultura no município, onde chegou a representar 49\% do PIB municipal em 2003 (Sampaio et al, 2008).

Apesar da menor área de cultivo registrada neste estudo, a produção de camarão cultivado do Vale do Rio Açu apresentou um incremento de aproximadamente $66 \%$, saindo de 3.792 toneladas no censo de 2011 (ABCC, 2013) chegando a 6.294,1 toneladas em 2013 (Tabela 01). Esse acréscimo da produção, obtido com maiores densidades de cultivo praticadas por parte dos produtores da Região, foi motivado pelo bom momento do mercado interno, que naquele ano segundo os relatos dos produtores proporcionava uma boa margem de lucro para a atividade. Estes dados estão em concordância com estudos de avaliação econômica da carcinicultura no realizados em 2010 que constataram o momento de recuperação pelo qual passava a atividade impulsionada pela demanda interna aquecida, bons preços de venda para o camarão e as boas condições macroeconômicas do país (Bezerra, 2010).

De acordo com o questionário aplicado a atividade gerava um total de 661 empregos diretos em 2013, sendo o município de Pendências o que apresentou o maior número, 449 empregos, seguido de Carnaubais com 132, Macau com 78 e Alto do Rodrigues com 2 (Tabela 02).

Os resultados demonstram que a carcinicultura na Região do Vale do Açu gerou, em 2011, 0,36 empregos diretos continuados por hectare de viveiro em produção, agrupados em 03 setores das empresas: Trabalho de campo, serviços administrativos e vigilância. Em sua maioria estes empregos são ocupados por mão de obra local com baixo nível de escolarização permitindo o acesso ao emprego formal por parte de trabalhadores com pouca qualificação. Foram desconsiderados neste cálculo empregos gerados em outros elos da cadeia produtiva do cultivo de camarão, como laboratórios de larvicultura, unidades de beneficiamento e cadeia de comercialização, assim como a contratação de serviços temporários. 


\begin{tabular}{|c|c|}
\hline Município & Número de empregos \\
\hline Macau & 78 \\
\hline Pendências & 449 \\
\hline Carnaubais & 132 \\
\hline Alto do Rodrigues & 02 \\
\hline Total & 661 \\
\hline
\end{tabular}

Tabela 02- Número de empregos diretos gerados nas fazendas de camarão do Vale do Açu em cada município.

Costa e Sampaio (2004) avaliaram a geração de empregos diretos na cadeia produtiva do camarão marinho cultivado no Brasil nos anos de 2002 e 2003 calculando que neste período a atividade gerava em média 1,0 emprego/ha (Emprego direto considerando apenas engorda), sendo este índice menor em fazendas de grande porte devido à economia de escala. Neste estudo ele demonstrou que a carcinicultura gerava um número de empregos por hectare muito superior a outras atividades tradicionais no Nordeste como a fruticultura $(0,42$ emprego/ha na produção de manga e 0,16 na produção de coco) e produção de cana-de-açúcar (0,35 emprego/ha).

O menor número de empregos por hectare observado na região do Vale do Açu em 2011 quando comparado com o estudo de Costa e Sampaio (2004) está diretamente relacionado com a presença de empresas de médio e grande porte na região (Tabela 03), que empregam proporcionalmente menos mão de obra que as de menor porte e também reflete uma adaptação das empresas ao momento atual da atividade, forçadas diminuir o número de empregados e melhorar sua produtividade a fim de reduzir seus custos de produção para alcançar um preço competitivo no abastecimento do mercado interno.

Ao se avaliar a atividade de carcinicultura praticada na área de estudo considerando o porte das unidades produtivas, observa-se que a maior parte delas $(80 \%)$ é de médio e grande porte. As empresas de grande porte concentram $88,7 \%$ da área destinada aos cultivos e 90,5\% da produção (Tabela 03).

\begin{tabular}{lcccccc}
\hline Categoria & Número de produtores & $\%$ & Área $(\mathrm{Ha})$ & $\%$ & Produção (Ton) & $\%$ \\
\hline Micro & 02 & 10,0 & 6,0 & 0,3 & 21,4 & 0,3 \\
Pequeno & 02 & 10,0 & 20,0 & 1,1 & 78,0 & 1,2 \\
Médio & 07 & 35,0 & 181,7 & 9,9 & 503,9 & 8,0 \\
Grande & 09 & 45,0 & $1.636,0$ & 88,7 & $5.690,8$ & 90,5 \\
Total & 20 & 100 & $1.843,7$ & 100 & $6.294,1$ & 100 \\
\hline
\end{tabular}

Tabela 03- Número de produtores, área e produção absolutos e relativos no ano de 2013 por categoria de porte do empreendimento.

A participação majoritária de fazendas de médio e grande porte na região estudada é uma característica marcante da carcinicultura do Vale do Açu e diverge dos resultados registrados no estado do Rio Grande do Norte como um todo pelo censo de 2011 , em que $46,5 \%$ de todos os empreendimentos do estado estavam na categoria de micro produtores (ABCC, 2013).

Os empreendimentos localizados na área de estudo apresentaram uma forte variação quando consideramos a salinidade da água empregada no cultivo. Como esperado, as fazendas localizadas mais próximas à foz, utilizam água com salinidades maiores que àquelas localizadas rio acima. Entretanto as fazendas localizadas em Macau (Próximas à foz) apresentaram uma 
salinidade particularmente elevada caracterizando um ambiente hiperhalino, com salinidade média acima de $40 \mathrm{~g} / \mathrm{l}$ na maior parte do ano e chegando, em alguns casos, a mais de $60 \mathrm{~g} / \mathrm{l}$ nos meses mais secos e de maiores taxas de evaporação, condições que contribuem para concentração dos sais presentes na água armazenada nos viveiros.

À medida que aumenta a distância das fazendas da foz do rio cresce a influência da agua doce diminuindo a salinidade da água utilizada no abastecimento dos viveiros, passando por fazendas que utilizam águas mesohalinas $(3,1-16,5 \mathrm{~g} / \mathrm{L})$ e polihalinas $(16,6-30 \mathrm{~g} / \mathrm{L})$, no município de Pendências, chegando ao ponto de utilização de água praticamente doce, com salinidades iguais ou inferiores a $0,5 \mathrm{~g} / \mathrm{l}$ como na quase totalidade das fazendas de Carnaubais. Também foi registrada nesta pesquisa a primeira fazenda de carcinicultura no Município de Alto do Rodrigues. Esta é atualmente a fazenda localizada a maior distância do litoral trabalhando exclusivamente com água doce e embora seja um microprodutor, com apenas 3 ha, sua localização pode ser indício de um movimento inicial de expansão da atividade em direção ao interior do continente (Tabela 04).

\begin{tabular}{lcccccc}
\hline Categoria & Salinidade g/I & Macau & Pendências & Carnaubais & Alto do Rodrigues & Total \\
\hline Doce & $\leq$ a 0,5 & - & 02 & 07 & 01 & 10 \\
Oligohalina & $0,5-3,0$ & - & - & - & - & - \\
Mesohalina & $3,1-16,5$ & - & 02 & 01 & - & 03 \\
Polihalina & $16,6-30$ & - & - & 01 & - & 01 \\
Eurihalina & $30,1-40$ & - & - & - & - & - \\
Hiperhalina & $\geq$ a 40,1 & 06 & - & - & - & 06
\end{tabular}

Tabela 04- Número de fazendas por categoria de salinidade das águas utilizadas (Boyd, 2001) nos municípios do vale do Rio Açu.

O L. vannamei é uma espécie tipicamente eurialina tolerando alta variação de salinidade e entre as espécies de camarões marinhos cultivados nas Américas é provavelmente a que melhor se adapta aos cultivos em baixas salinidades (Macgraw, Davis, Teichert-Coddington \& Rouse, 2002). Os resultados comprovam a grande capacidade de osmorregulação da espécie que na região é cultivada em fazendas com águas hiperhalinas, fazendas com águas meso-polihalinas e fazendas com águas doces.

A expansão do cultivo de L. vannamei em áreas cada vez mais distantes do litoral utilizando água doce de rios, barragens e poços é uma tendência global. Os altos custos das áreas costeiras, assim como as restrições impostas pelas regulamentações ambientais limitam a expansão da aquicultura em regiões próximas ao litoral (Sowers et al, 2005). Estas limitações somadas à habilidade do L. vannamei de tolerar larga variação de salinidade, que o consagraram como espécie popular para cultivos em água doce, ampliaram as fronteiras de expansão da carcinicultura rumo ao interior do continente (Fonseca, Mendes, Albertim, Bittencurt \& Silva, 2009).

Esta realidade está bem configurada no Vale do Açu e provavelmente essa expansão não é mais intensa devido à insegurança no fornecimento de água doce a partir da Barragem Armando Ribeiro Gonçalves, localizada rio acima, e administrada pelo Departamento Nacional de Obras Contra a Seca (DNOCS). Este fornecimento diminui drasticamente quando a barragem 
atinge níveis considerados críticos, situação que aconteceu nos anos de 2015 e 2016, se tornando um fator limitante para o crescimento da atividade e inserindo a carcinicultura em conflitos pelo uso da água do Rio Açu que também é utilizada para a atividade de fruticultura irrigada e o abastecimento humano de vários municípios da Região.

Do ponto de vista do nível tecnológico empregado nos empreendimento de carcinicultura entrevistados, $60 \%$ deles utilizam berçários para pós-larvas antes do povoamento dos viveiros, $35 \%$ utiliza aeradores nos viveiros de engorda para incremento de oxigênio dissolvido na água em alguma fase da engorda, $40 \%$ utiliza probióticos, $80 \%$ realiza análise hidrológica durante os cultivos, $45 \%$ realiza análises presuntivas frequentemente como método de acompanhamento da saúde dos camarões e tomada de decisões quanto ao manejo e $100 \%$ das fazendas utilizam comedouro na oferta da ração aos animais seja como único método de arraçoamento ou combinado com voleio.

Na comparação dos resultados do presente estudo com os dados anteriores mais recentes da carcinicultura potiguar obtidos pelo censo da carcinicultura brasileira de 2011 (ABCC, 2013) percebe-se que no Vale do Açu a utilização de berçários, comedouros e realização de análises de água foram muito mais frequentes em 2013 , enquanto o uso de probióticos permaneceu estável e a utilização de aeradores e a realização de análises presuntivas foram menores (Tabela 05).

\begin{tabular}{lcccccc}
\hline $\begin{array}{c}\text { Fonte dos dados } \\
\text { e }\end{array}$ & $\begin{array}{c}\text { Uso de } \\
\text { berçários }\end{array}$ & $\begin{array}{c}\text { Uso de } \\
\text { Aeradores }\end{array}$ & $\begin{array}{c}\text { Uso de } \\
\text { probióticos }\end{array}$ & $\begin{array}{c}\text { Realiza } \\
\text { Análises } \\
\text { Hidrológicas }\end{array}$ & $\begin{array}{c}\text { Realiza } \\
\text { Análises } \\
\text { Presuntivas }\end{array}$ & $\begin{array}{c}\text { Uso de } \\
\text { Comedouros }\end{array}$ \\
\hline ABCC, 2011 & $11 \%$ & $61 \%$ & $41 \%$ & $36 \%$ & $57 \%$ & $83 \%$ \\
Próprios, 2013 & $60 \%$ & $35 \%$ & $40 \%$ & $80 \%$ & $45 \%$ & $100 \%$ \\
\hline
\end{tabular}

Tabela 05- Porcentual de utilização dos Indicadores de tecnologia avaliados. Acima dados do censo da ABCC de 2011 para o RN e abaixo resultados registrados por este estudo para o Vale do Açu.

A maior utilização de berçários, comedouros e análises de água observada na Bacia do Açu em 2013 são indicadores de um elevado patamar tecnológico e possibilitam ganhos na produtividade. Silva e Sampaio (2009) ressaltam que aperfeiçoamentos como estes no sistema produtivo aumentam a eficiência e competitividade da carcinicultura e podem até mesmo proporcionar redução dos impactos ambientais gerados. Entretanto, estes benefícios são mais acessíveis às empresas de maior porte por terem maior capacidade de investimentos e de contratação de assistência técnica. O perfil observado neste estudo com empresas majoritariamente de médio e grande porte comprova a capacidade econômica para aprimoramento tecnológico como o observado no uso de berçários que permitem ampliação da produção diminuindo o período de engorda nos viveiros e consequentemente um maior número de ciclos de cultivo por ano. O bom momento econômico que a atividade vivenciava a partir de 2010 (Bezerra, 2010) também pode estar relacionado com o aprimoramento tecnológico observado.

A utilização mais intensa de tecnologias na produção de camarão tem como objetivo imediato dos produtores o aumento da lucratividade, mas a maior eficiência e produtividade permitem o aumento da produção sem necessariamente ampliar as áreas de cultivo (diminui a pressão sobre novas áreas) e possibilita a minimização do impacto causado por seus efluentes (Menor emissão de fosfatos e nitrato com utilização correta de rações balanceadas). MartinezCordero \& Leung (2005) ressaltam que o grande desafio que se coloca para o crescimento 
sustentável da carcinicultura, atividade sempre lembrada pelos impactos ambientais que causa, é produzir com a máxima eficiência e produtividade e o mínimo de impactos ao meio ambiente.

Das 20 fazendas avaliadas através dos questionários 19 delas destinam integralmente sua produção para o mercado brasileiro $(97,2 \%)$ e apenas 01 declarou ter exportado, no ano de 2013 , $5 \%$ de sua produção, ou 238 toneladas, equivalentes a 2,8\% do total produzido no Vale do Açu neste ano. Nos casos da comercialização no mercado brasileiro a compra é feita por comerciantes que adquirem o camarão fresco e o transportam refrigerado em caminhões para os estados consumidores, sem que passe por qualquer tipo de processamento.

Foram declarados como principais estados consumidores do camarão produzido no Vale do Açu os estados do Rio de Janeiro e São Paulo, mas também são citados Bahia, Paraná, Paraíba e o próprio Rio Grande do Norte.

Estes resultados estão de acordo com os observados em outros estados produtores. Segundo Tahim \& Araújo (2014) a comercialização da produção brasileira de camarão no mercado interno que era 31\% em 2004 passou para 99\% em 2011. Quando as exportações brasileiras de camarão cultivado entraram em declínio a demanda interna por camarão se tornou imprescindível para a continuidade, e retomada do crescimento, da carcinicultura nacional (Bezerra, 2010) que em 2013 produziu 85.000 t aproximando-se de nossa maior produção obtida no ano de 2003, que foi de 90.190 t (Rocha, 2014). Entretanto como pouco desta produção é processada no Rio Grande do Norte as indústrias de beneficiamento de camarão que ainda estão ativas no estado continuam trabalhando abaixo de sua capacidade de produção que em 2011 era de 7.860 t/mês, correspondente a 38,7\% da capacidade nacional (ABCC, 2013).

Quando questionadas sobre quais enfermidades já causaram impacto negativo sobre a produção, a mais citada foi a Mionecrose Infecciosa Viral (IMNV), com relatos em 90\% das fazendas, Vibrioses vem em segundo lugar citada por $50 \%$ das fazendas e em terceiro a Hepatopancreatite Necrosante (NHP) com 15\%. Outras patologias citadas foram: Necrose com 10\%, Vírus da Mancha Branca (WSSV) e Gregarina ambas em 5\% (Tabela 06).

Os relatos coincidem com resultados de outros estudos que listaram as principais patologias que afetam a carcinicultura brasileira (Apolinário, 2009; Nunes, Martins \& Gesteira, 2004; Nunes, Madrid \& Andrade, 2005) e mundial (Pantoja \& Lightner, 2008; Flegel, 2012). Entretanto, chama atenção a declaração de ocorrência de WSSV, durante a aplicação do questionário em maio de 2013, por parte de um responsável técnico de uma das fazendas da região, que até o momento não tinha sido afetada por esta patologia. Segundo o relato o WSSV não chegou a causar mortalidade expressiva e foi diagnosticada através análise presuntiva pelo técnico que vivenciou um surto dessa patologia no Equador, e possui larga experiência de campo e acadêmica sobre o assunto. Embora não tenha sido feita uma análise confirmatória que apoie este diagnóstico ele ganha relevância com o fato de o WSSV ter sido registrado amplamente a partir de junho de 2015 em toda a região causando grandes prejuízos.

\begin{tabular}{|c|c|c|}
\hline Patologia & Fazendas afetadas & $\%$ \\
\hline IMNV & 18 & 90 \\
\hline Vibriose & 10 & 50 \\
\hline NHP & 3 & 15 \\
\hline Necrose & 2 & 10 \\
\hline WSSV & 1 & 5 \\
\hline Gregarina & 1 & 5 \\
\hline
\end{tabular}

Tabela 06 - Patologias que afetam a produção de camarão no Vale do Açu, com número e porcentual de fazendas afetadas por cada patologia. 
Questionados sobre qual doença causou maior impacto sobre a produção de camarão $55 \%$ dos representantes das fazendas apontaram a IMNV, 25\% a Vibriose, 5\% a NHP e $15 \%$ por cento não soube responder. Sobre riscos futuros com patologias $65 \%$ apontaram WSSV como maior risco, $10 \%$ respondeu IMNV, 5\% Vibriose e $20 \%$ não responderam. A preocupação demonstrada em 2013 com WSSV era reflexo dos grandes prejuízos que a enfermidade já vinha causando em outras regiões do Brasil desde 2005, incluindo áreas localizadas no Litoral sul do Rio Grande do Norte (Nunes et al, 2005; Muller, Andrade, Tang-Nelson, Marques \& Lightner, 2010) e infelizmente desde meados de 2015 é uma realidade com a qual os produtores da Bacia do Açu estão tendo que lidar e de consequências ainda não quantificadas em termos de queda na produção e impacto social.

As patologias que atacam os camarões nos cultivos são hoje um dos maiores problemas do setor uma vez que as altas taxas de mortalidade diminuem a lucratividade ou, em alguns casos, inviabilizam a atividade. Natori et al (2011) reforça que as enfermidades constituem atualmente um desafio para a carcinicultura e afirma que no caso brasileiro a intensificação dos sistemas produtivos em atividade é o motivo para maior ocorrência dos surtos. Entretanto Pantoja e Lightner (2008) afirmam que no futuro os cultivos de camarão em sistemas intensivos e superintensivos, realizados em instalações projetadas para esta finalidade, serão mais competitivos por permitirem um maior controle dos parâmetros de qualidade de água e uma aplicação mais efetiva dos métodos de biossegurança.

No Rio Grande do Norte algumas empresas têm investido em sistemas de cultivo intensivo de produção, baseado no modelo asiático, como forma de continuar produzindo camarão com altas densidades de povoamento mesmo em regiões onde o IMNV e WSSV estão presentes. Este modelo utiliza viveiros lonados, água tratada para eliminação de potenciais vetores, pós-larvas livres de patógenos específicos (SPF) em densidades de 80 a 120 camarões $/ \mathrm{m}^{2}$ e são adotados rigorosos controles de biossegurança. Guerrelhas, Teixeira e Godoy (2011) relatam que, em um estudo sobre a utilização em escala comercial deste sistema em uma empresa localizada no Litoral Sul do Rio Grande Norte em 2010, os resultados preliminares de sobrevivência $(78,1 \%)$ e produtividade $(9,8 \mathrm{t} / \mathrm{ha} /$ ciclo de 100 dias) foram bastante satisfatórios e apontaram este modelo como uma alternativa viável para aumentar a produção nacional mesmo em áreas afetadas pelo WSSV.

\section{CONCLUSÕES}

A região do Vale do Açu constitui um importante polo de produção de camarão de cultivo no estado do Rio Grande do Norte e os resultados desta pesquisa mostram que até 2013, ano da coleta dos dados, a atividade passava por um processo de ampliação na produção em comparação com os dados do censo de 2011, resultante principalmente da intensificação dos sistemas de cultivo uma vez que não foi constatada ampliação da área usada pela carcinicultura no período.

A carcinicultura continua sendo uma importante geradora de emprego no Vale do Baixo Açu e é constituída principalmente por fazendas de médio e grande porte. Os cultivos utilizam águas com salinidades que variam de hiperhalina a doce sendo que a inconstância no abastecimento de água doce se apresenta como um fator limitante para a ampliação da atividade nas localidades mais afastadas do litoral. 
O nível tecnológico da maior parte dos empreendimentos de carcinicultura do Vale do Açu pode ser considerado elevado a demanda interna por camarão, principalmente dos estados do Sudeste, é responsável direta pelo revigoramento da carcinicultura na região.

As patologias constituem um grande desafio para a carcinicultura local, assim como ocorre em todo o mundo. O risco sempre presente de surtos de velhas e novas doenças impõe aos carcinicultores algumas incertezas quanto ao futuro da atividade e o desafio de encontrar um nível de intensificação de produção que permita uma boa lucratividade sem degradação das condições de cultivo do camarão que favorecem a ocorrência de surtos.

\section{REFERÊNCIAS}

ABCC. (2013). Levantamento da infraestrutura produtiva e dos aspectos tecnológicos, econômicos, sociais e ambientais da carcinicultura marinha no Brasil em 2011. ABCC/MPA, Natal, RN.

APOLINÁRIO, D. F. (2009). Avaliação do estado sanitário de camarões (Litopenaeus vannamei) cultivados em quatro fazendas no estado do Ceará. Dissertação apresentada ao curso de Ciências Marinhas Tropicais. Universidade Federal do Ceará, LABOMAR-UFC, Fortaleza, 2009.

BEZERRA, M. A. (2010). A retomada da carcinicultura no Brasil: Vivemos uma nova realidade econômica financeira nas unidades produtoras de camarão no Nordeste Brasileiro? Revista Panorama da Aquicultura, 20(121), 54-59.

BOYD, C. E. (2001). Manejo da qualidade de água na aquicultulra e no cultivo do camarão marinho (Rodrigues, J. Trad.). Associação Brasileira de Criadores de Camarão. (ABCC) (157 pp. 2001) Recife.

COSTA, E. F.; SAMPAIO, Y. S. B. (2004). Geração de empregos diretos e indiretos na cadeia produtiva de camarão marinho cultivado. Revista de Economia Aplicada, 8(2), 327-345.

FAO. (2014). FAO yearbook 2012, Fisheries and aquaculture statistic. 2014. Disponível em: < ftp://ftp.fao.org/FI/CDrom/CD_yearbook_2012/navigation/index_content_aquaculture_e.ht $\mathrm{m \# C}>$ Acesso em: 10 jun. 2015.

FAO. (2015a). World aquaculture production by species groups in 2013. Disponível em: < ftp://ftp.fao.org/FI/STAT/summary/b-1.pdf> Acesso em: 9 jun. 2015.

FAO. (2015b). World aquaculture production of fish, crustaceans, molluscs, etc; by principal species in 2013. Disponível em: < ftp://ftp.fao.org/FI/STAT/summary/a-6.pdf> Acesso em: 9 set. 2015.

FLEGEL, T. W. (2012). Historic emergence, impact and current status of shrimp pathogens in Asia. Journal of Invertebrate Pathology, 110, 166-173.

FONSECA, S.B., MENDES, P.P., AlBertiM, C. J. L., BITTENCURT, C. F. \& SILVA, J. H. B. (2009). Cultivo do camarão marinho em água doce em diferentes densidades de estocagem. Pesq. Agropec. Bras., 44(10), 1352-1358.

GUERRELHAS, A. C. B.; TEIXEIRA, A. P. G.; GODOY. E. (2011). Cultivo intensivo: Pode ser a solução para o aumento da produção da carcinicultura? Revista Panorama da Aquicultura, 21(123), 52-57. 
MACGRAW, W. J.; DAVIS, D. A.; TEICHERT-CODDINGTON, D. ROUSE, D. B. (2002) Acclimtion of $L$. vannamei postlarvae to low salinity: Influence of age, salinity end point, and rate of salinity reduction. Journal of the World Aquaculture Society, 33(1).

MARTINEZ-CORDERO, F. J. \& LEUNG, P. (2005). Production performance indicators with externalities: Environmentally-adjusted productivity and efficiency indicators of a sample of semi-intensive shrimp farms in Mexico. Aquaculture, (241), 249-268.

MULLER, I. C., ANDRADE, T. P. D., TANG-NELSON, K. F. J., MARQUES, M. R. F. \& LIGHTNER, D. V. (2010). Genotyping of white spot syndrome virus (WSSV) geographical isolates from the Americas. Dis. Aquat. Org. (vol. 88, pp. 91-98, jan, 2010).

NATORI, M. M., SUSSEL, F. R., SANTOS, E. C. B., PREVIERO, T. C., VIEGAS, E. M. M. \& GAMEIRO, A. H. (2011). Desenvolvimento da carcinicultura marinha no Brasil e no mundo: Avanços tecnológicos e desafios. Informações econômicas, 41(2), 61-73.

NUNES, A. J. P., MARTINS, P. C. C. \& GESTEIRA, T. C. V. (2004). Carcinicultura ameaçadaProdutores sofrem com as mortalidades decorrentes do Virus da Mionecrose Infecciosa. Revista Panorama da Aquicultura, 14(83), 37-51.

NUNES, A. J. P., MADRID, R. M. \& ANDRADE, T. P. (2005). Carcinicultura marinha no Brasil: Passado, presente e futuro. Revista Panorama da Aquicultura, 21(124), 26-33.

PANTOJA, C. R. \& LIGHTNER, D. V. (2008). Enfermedades Virales. En: Morales, V. y Cuéllar-Anjel, J. (eds). Guia Técnica - Patologia e imunologia de camarones Penaeidos. Programa CYTED-Red II-D: Vannamei, Panamá, Rep. Panamá.

ROCHA, I. P. (2010). Shrimp Farm in Brazil- Burgeoning Industry Recovering, Future Holds Potential. Global Aquaculture Advocate, September/October, 2010, 43-45.

ROCHA, I. P. (2014). Uma análise da importância da aquicultura e de forma especial, da carcinicultura, para o fortalecimento do setor pesqueiro e da sócio economia primária brasileira. Revista da ABCC, ano XVI (3), 22-28.

RODRIGUES, J.; BORBA, M. (2015). Carcinicultura brasileira: Estatísticas e revelações. Coletânea de artigos sobre a indústria do camarão cultivado. Associação Brasileira de Criadores de Camarão (ABCC). Natal, 2015.

SAMPAIO, Y., COSTA, E. F., ALBUQUERQUE, E. \& SAMPAIO, B. R. (2008). Impactos socioeconômicos do cultivo de camarão marinho em municípios selecionados do Nordeste brasileiro. RESR, 46(4), 1015-1042.

SILVA, J. L. M. \& SAMPAIO, L. M. B. (2009). Eficiência, gestão e meio ambiente na carcinicultura do Rio Grande do Norte. RESR, 47(4), 883-902.

SOWERS, A. D.; GATLIN, D. M.; YOUNG, S. P.; ISLEY, J. J.; BROWDY, C. L.; TOMASSO, J. R. (2005). Responses of Litopenaeus vannamei (Boone) in water containing low concentrations of total dissolved solids. Aquaculture Research, 36, 819-823.

TAHIM, E. F, \& ARAÚJO JR, I.F. (2014). A carcinicultura do Nordeste brasileiro e sua inserção em cadeias globais de produção: Foco nas APLs do Ceará. RESR, 52(3), 567-586. 